ORIGINAL ARTICLE

\title{
Quality of Life After Intensive Care Unit Discharge in a Tertiary Care Hospital in India: Cost Effectiveness Analyis
}

\author{
Shakti Bedanta Mishra ${ }^{1}$, Banani Poddar ${ }^{2}$, Rajesh Kasimahanti ${ }^{3}$, Afzal Azim ${ }^{4}$, Ratender Kumar Singh ${ }^{5}$, Mohan Gurjar ${ }^{6}$, \\ Arvind Kumar Baronia ${ }^{7}$
}

\begin{abstract}
Background: Improvements in intensive care in the last few decades have shifted the focus from mortality to quality of life of survivors as a more important outcome measure. Allocation of public resources towards intensive care is an important challenge for health care administrators. This challenge is made more arduous in resource limited countries like India. Thus, it is imperative to consider patient centred outcomes and resource utilisation to guide allocation of funds. The aim of this study was to evaluate the quality of life of long-term survivors, and to perform cost-effectiveness and cost-utility analysis.

Methods: Data was retrieved from the records and included age, gender, admission diagnosis, length of ICU stay \& mortality. Costing methodology used was top down approach. Quality of life was assessed by SF 36 scoring which was done with personal interview and telephonically. Cost effectiveness analysis was done on the basis of years of life added. Cost utility was done by QALY gained.

Results: A total of 1232 adult patients were admitted in the period with 758 (61\%) being successfully discharged from ICU with a mortality rate of $39 \%$. Out of 758 , we could contact $113(15 \%)$ patients. 86 patients were alive at the time of contact who could fill the forms for quality of life. The patients discharged from ICU had scores almost similar to the general population. Lesser scores were noted in physical functioning and general health perceptions, though this difference was not statistically significant. The life years gained were significantly more in younger patients. The cost per life gained was more in patients aged more than 50 years compared to those who were younger.

Conclusion: The quality of life after survival from ICU is as good as in the general population. The intensive care provided in our ICU is cost effective.

Indian Journal of Critical Care Medicine (2019): 10.5005/jp-journals-10071-23133
\end{abstract}

\section{INTRODUCTION}

$\mathrm{M}$ ortality is one of the most important outcome parameters measured in the intensive care unit (ICU) ${ }^{1,2}$. Improvements in intensive care in the last few decades have shifted the focus from mortality to quality of life of survivors as a more important outcome measure $^{3}$. There have been numerous studies from developed nations on the quality of life following survival after ICU stay, similar studies from developing countries like India are scarce ${ }^{4-6}$.

Further, since intensive care utilises a large amount of resources for a limited number of patients, the need to know how intensive care therapy has influenced the quality of life of survivors becomes very important. Allocation of public resources towards intensive care is an important challenge for health care administrators. This challenge is made more arduous in resource limited countries like India. Thus, it is imperative to consider patient centred outcomes and resource utilisation to guide allocation of funds.

The aim of this study was to evaluate the quality of life of longterm survivors, and to perform cost-effectiveness and cost-utility analysis.

\section{Patients and Methods}

The study protocol was approved by the Institute ethics committee of the Sanjay Gandhi Post Graduate Institute of Medical Sciences, Lucknow, India. Consecutive patients who stayed more than 24 hours in the ICU of the Department of Critical Care Medicine between June 2005 and May 2010 were eligible for study entry. Data retrieved included age, gender, admission diagnosis, length of ICU stay \& mortality. Patients who died within 2 years of discharge from ICU were termed as non survivors and were not included in
${ }^{1}$ Department of Critical Care Medicine, IMS and SUM Hospital, Bhubaneswar, Odisha, India.

${ }^{2,4-7}$ Department of Critical Care Medicine; Sanjay Gandhi Post Graduate Institute of Medical Sciences (SGPGIMS), Lucknow, Uttar Pradesh, India. ${ }^{3}$ Department of Critical Care Medicine; Yashoda Hospital, Secunderabad, Telangana, India.

Corresponding Author: Banani Poddar, Professor, Department of Critical Care Medicine; Sanjay Gandhi Post Graduate Institute of Medical Sciences (SGPGIMS), Raebareli Road, Lucknow, Uttar Pradesh, India, e-mail: bananip@hotmail.com

How to cite this article: Mishra SB, Poddar B et al, Quality of Life After Intensive Care Unit Discharge in a Tertiary Care Hospital in India: Cost Effectiveness Analysis. Indian J of Crit Care Med 2019;23(3):122-126.

Source of support: Nil

Conflict of interest: None

our analysis. Costing methodology used was top down approach. Here the cost that was borne by each patient was included as the cost of therapy. The cost was of the ICU stay duration only and not of the complete hospital stay.

\section{Quality of Life and Health Status Index}

We extracted patients' contact information like telephone numbers and address from our database. We tried to contact them telephonically and sent letters to their addresses. Patients who came to the hospital for follow up in other departments were interviewed personally, and telephonic interviews were done if required. If patients did not come to the hospital and/or telephone contact could not be established, then a formal letter

(O) The Author(s). 2019 Open Access This article is distributed under the terms of the Creative Commons Attribution 4.0 International License (http://creativecommons. org/licenses/by/4.0/), which permits unrestricted use, distribution, and non-commercial reproduction in any medium, provided you give appropriate credit to the original author(s) and the source, provide a link to the Creative Commons license, and indicate if changes were made. The Creative Commons Public Domain Dedication waiver (http://creativecommons.org/publicdomain/zero/1.0/) applies to the data made available in this article, unless otherwise stated. 
was sent accompanied by a return envelope and the validated Hindi/English interview form of the Medical Outcome Survey Short Form-36 questionnaire (SF-36) ${ }^{7,8}$ self-report form. QOL was assessed by means of the Medical Outcomes Study 36-item Short Form Health Survey (SF-36v2 ${ }^{\circledR}$ ). The SF-36 questionnaire contains 36 items measuring eight health domains: physical(PF) and social functioning (SF), role limitations due to physical (RP) or emotional problems (RE), mental health (MH), vitality (VT), bodily pain (BP), and general perception of health (GH). Two component scores,a physical (PCS) and a mental (MCS), are calculated summary scores where, respectively, the physical domains $(\mathrm{PF}, \mathrm{RP}, \mathrm{BP}, \mathrm{GH})$ or the mental domains (VT, SF, RE, MH) will account more in the score. For a few patients, the same form was sent on email and the completed form was returned to us. Death of the patient was confirmed from relatives wherever this had occurred.

Based on the SF-36, a health status index was calculated for each patient. A health status index assigns a weight ranging from 0 (in difference between life and death) to 1 (perfect health) corresponding to the overall quality of life. In this study, the proportion of the SF-36 in each of the eight domains was set against the measures of an age-matched group of apparently healthy subjects.

\section{Cost-Effectiveness and Cost Utility}

The comparison of cost effectiveness analysis with a comparator group requires similar treatment strategy or drugs. Since this was an observational study, no comparator group was available. The results are therefore based on the assumption that patients would have died without ICU care. To estimate the cost per life year gained, the costs per survivor were divided by the estimated life years gained. The remaining life span of the patients was calculated based on an average age-adjusted life expectancy of $64.3 \mathrm{yrs}$. for males and 66.4 yrs. for females ${ }^{9,10}$

Cost utility analysis is a cost effectiveness analysis in which the quality of life of the patient is utilised to compare the associated cost. It is usually estimated in terms of life years gained and QALY (Quality adjusted Life Years) ${ }^{11}$. A QALY is the product of the number of years of life times the health status index. Costs per QALY were calculated according to the health status index of the patients surviving ${ }^{12}$.

Statistical Analysis: All variables were tested for normal distribution with the Kolmogorov-Smirnov test. Descriptive statistics include mean and SD values except when stated otherwise. Student's t-test was used to compare means of continuous normally distributed data. A nonparametric rank test (Mann-Whitney $U$ test) was applied in case of non-normally distributed data. Categorical data were tested using the chi-square statistic with Yates correction when appropriate. Risk factors were dichotomised to do the cost and risk analysis.

All statistical tests are two-sided, and a significance level of $p$ $<0.05$ or less was applied, except when stated otherwise. Data were analysed using SPSS 21.0 (SPSS, Chicago, IL).

\section{Results}

The flow chart of patients included in this study is depicted in Figure 1. Table 1 illustrates the demographic characteristics of all the patients admitted to the ICU during the period of June 2005 to May 2010. A total 1232 adult patients were admitted in the period with 758 (61\%) being successfully discharged from ICU with a mortality rate of $39 \%$. Out of 758 , we could contact $113(15 \%)$ patients. 86 patients were alive at the time of contact who could fill the forms for quality of life.

Figure 2 shows the quality of life as evaluated through SF-36 in comparison to the normal general population in a spider diagram. The scoring is divided into 8 parts i.e. vitality (VT), physical functioning (PF), bodily pain (BP), general health perceptions (GH), physical role functioning (RP), emotional role functioning (RE),

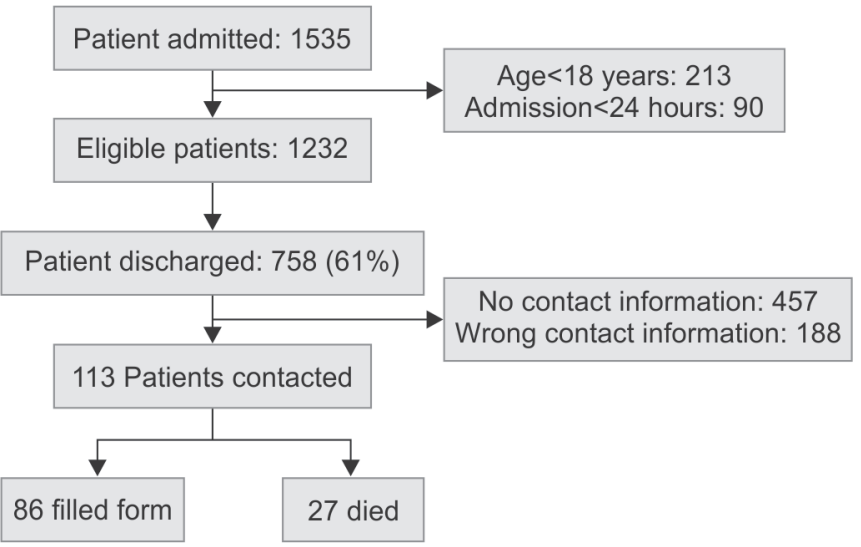

Fig. 1: Flow diagram showing how the patients were included

Table 1: Demographic Profile

\begin{tabular}{llll}
\hline & All Patients & Discharged & Contacted \\
\hline Number & 1232 & 758 & 113 \\
M:F & $818(66): 414(34)$ & $529(70): 229(30)$ & $70(62): 43(38)$ \\
Age (mean $\pm \mathrm{sd})$ & $48.4 \pm 16.9$ & $48.5 \pm 16.8$ & $44.1 \pm 17.1$ \\
Diagnosis & & & \\
Tropical Illness & $236(19.1 \%)$ & $162(21.3 \%)$ & $16(14.2 \%)$ \\
SAP & $289(23.4 \%)$ & $118(15.5 \%)$ & $25(22.1 \%)$ \\
Neurological & $152(12.3 \%)$ & $101(13.3 \%)$ & $15(13.3 \%)$ \\
Sepsis & $402(32.6 \%)$ & $285(37.5 \%)$ & $35(31.0 \%)$ \\
Liver & $86(6.9 \%)$ & $37(4.8 \%)$ & $4(3.5 \%)$ \\
Others & $67(5.4 \%)$ & $55(7.2 \%)$ & $18(15.9 \%)$ \\
\hline
\end{tabular}

All values are in number (percentages) else specified. SD: Standard deviation. M: Male. F:Female. SAP: Severe Acute Pancreatitis. 
Quality of Life After Intensive Care Unit Discharge in a Tertiary Care Hospital in India: Cost Effectiveness Analyis

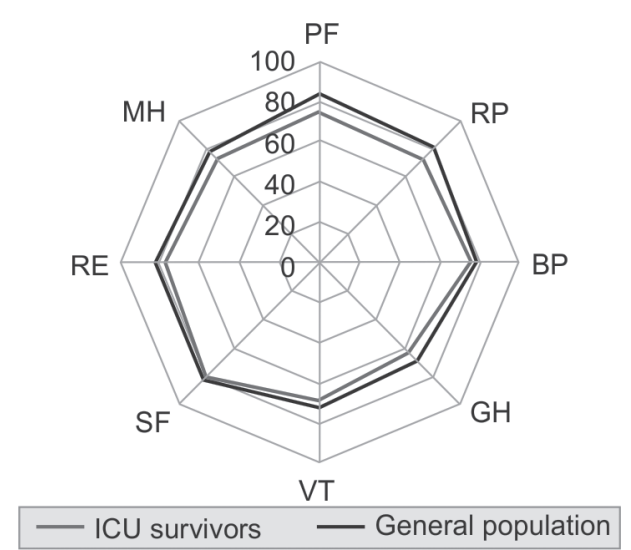

Fig. 2: Quality of life as evaluated through SF-36 in comparison to the normal general population

social role functioning (SF) and mental health (MH). The patients discharged from ICU had scores almost similar to the general population. Lesser scores were noted in physical functioning and general health perceptions, though this difference was not statistically significant.

The patients were dichotomised based on age ( $>50$ years and $\leq 50$ years), duration of mechanical ventilation ( $>7$ days and $\leq 7$ days) and stay in the ICU (>28 days and $\leq 28$ days). In patients who were older the physical functionality was worse. The patients who spent more time on mechanical ventilation had worse vitality and the patients who spent more time in the ICU had more bodily pain (Supplementary Tables 1-3).

Supplementary Table 1: SF 36 Scores based on days of mechanical ventilation (MV)

\begin{tabular}{llll}
\hline & $M V>7$ days & $M V \leq 7$ days & Pvalue \\
\hline $\mathrm{PF}^{1}$ & $75.1 \pm 22.4$ & $73.9 \pm 21.6$ & 0.8 \\
$\mathrm{RP}^{2}$ & $75.7 \pm 23.1$ & $70.0 \pm 23.7$ & 0.27 \\
$\mathrm{BP}^{3}$ & $77.8 \pm 26.3$ & $79.0 \pm 22.7$ & 0.25 \\
$\mathrm{GH}^{4}$ & $60.9 \pm 15.3$ & $66.1 \pm 13.8$ & 0.10 \\
$\mathrm{VT}^{5}$ & $64.9 \pm 18.2$ & $74.2 \pm 15.6$ & 0.01 \\
$\mathrm{SF}^{6}$ & $81.9 \pm 20.9$ & $76.6 \pm 23.2$ & 0.46 \\
$\mathrm{RE}^{7}$ & $79.0 \pm 23.8$ & $74.0 \pm 22.1$ & 0.26 \\
$\mathrm{MH}^{8}$ & $71.1 \pm 15.9$ & $74.4 \pm 15.7$ & 0.34 \\
$\mathrm{PCS}^{9}$ & $49.2 \pm 7.5$ & $49.9 \pm 7.1$ & 0.65 \\
$\mathrm{MCS}^{10}$ & $49.9 \pm 7.6$ & $50.4 \pm 7.2$ & 0.73 \\
\hline
\end{tabular}

Supplementary Table 2: SF 36 Scores based on length of stay (LOS) in ICU

\begin{tabular}{llll}
\hline & LOS $>28$ days & LOS $\leq 28$ days & $P$ value \\
\hline $\mathrm{PF}^{1}$ & $79.6 \pm 22.6$ & $75.1 \pm 21.0$ & 0.91 \\
$\mathrm{RP}^{2}$ & $70.9 \pm 25.5$ & $77.1 \pm 19.4$ & 0.24 \\
$\mathrm{BP}^{3}$ & $72.1 \pm 27.2$ & $83.0 \pm 18.0$ & 0.04 \\
$\mathrm{GH}^{4}$ & $62.0 \pm 17.0$ & $66.5 \pm 9.3$ & 0.17 \\
$\mathrm{VT}^{5}$ & $67.5 \pm 18.5$ & $73.0 \pm 15.0$ & 0.16 \\
$\mathrm{SF}^{6}$ & $79.1 \pm 23.0$ & $82.8 \pm 18.7$ & 0.45 \\
$\mathrm{RE}^{7}$ & $79.3 \pm 25.3$ & $81.7 \pm 18.0$ & 0.15 \\
$\mathrm{MH}^{8}$ & $72.2 \pm 16.4$ & $74.5 \pm 14.8$ & 0.51 \\
$\mathrm{PCS}^{9}$ & $48.9 \pm 7.8$ & $50.9 \pm 6.3$ & 0.22 \\
$\mathrm{MCS}^{10}$ & $49.5 \pm 7.9$ & $51.6 \pm 6.5$ & 0.19 \\
\hline
\end{tabular}

Table 2: Cost Utility analysis

\begin{tabular}{llll}
\hline & Age $>50$ yrs & Age $\leq 50$ yrs & $p$ value \\
\hline QALY gained & $5.3 \pm 0.8$ & $5.6 \pm 0.7$ & 0.23 \\
$\begin{array}{l}\text { Cost per QALY } \\
\text { gained (US\$) }\end{array}$ & $1413 \pm 65.8$ & $1319.6 \pm 61.3$ & 0.93 \\
$\begin{array}{l}\text { Life years gained } \\
\begin{array}{l}\text { Cost per life } \\
\text { years gained (US\$) }\end{array}\end{array}$ & $196.0 \pm 5.7$ & $32.7 \pm 7.9$ & $<0.01$ \\
\hline
\end{tabular}

All Values are in mean \pm standard deviation unless specified. QALY: Quality Adjusted Life Years. US\$: United States Dollars.

The cost analysis was done based on age dichotomization (Table 2). Patients were expected to die if they did not receive ICU admission. The QALY based on SF 6D was similar between the two groups. The cost per QALY gained was statistically similar between the two groups. The life years gained was calculated from data of WHO for India for the year 2015; i.e., average age-adjusted life expectancy of $64.3 \mathrm{yrs}$. for males and $66.4 \mathrm{yrs}$. for females. The life years gained were significantly more in younger patients. The cost per life gained was more in patients aged more than 50 years compared to those who were younger.

\section{Discussion}

In this follow up study of medical ICU patients, we found a quality of life of ICU survivors comparable to the general population. Further, the cost of ICU care provided seems reasonable.

The time course of physical and mental recovery after ICU stay is a highly individual process, and marked differences have been described in the literature. We have based our study on the recommendations of $\mathrm{ESICM}^{13}$. Thus, the long follow up in this study has perhaps been a) selective, to exclude patients who may have deteriorated early after their ICU stay; and b) sufficiently long to allow regaining of the best achievable quality of life.

To compile a rigorous cost-effectiveness analysis is a demanding task. There are many methodological intricacies to consider within the study, and the analysis is likely to be highly reliant on the availability and quality of both cost and outcome assessment. To date, our data represents the longest follow up study of ICU patients including cost-effectiveness and cost-utility analysis from India.

\section{Demographics}

The most common cause of admission in our ICU was sepsis followed by severe acute pancreatitis. Survival in ICU was better

\begin{tabular}{llll}
\multicolumn{4}{c}{ Supplementary Table 3: SF 36 scores based on age at time of admission } \\
\hline $\mathrm{PF}^{1}$ & Age $>50$ yrs & Age $\leq 50$ yrs & P value \\
$\mathrm{RP}^{2}$ & $61.6 \pm 25.4$ & $78.1 \pm 19.7$ & $<0.01$ \\
$\mathrm{BP}^{3}$ & $64.9 \pm 28.0$ & $75.4 \pm 21.4$ & 0.09 \\
$\mathrm{GH}^{4}$ & $67.1 \pm 24.9$ & $78.5 \pm 24.0$ & 0.08 \\
$\mathrm{VT}^{5}$ & $65.9 \pm 17.2$ & $63.1 \pm 14.1$ & 0.46 \\
$\mathrm{SF}^{6}$ & $70.5 \pm 16.4$ & $69.3 \pm 17.8$ & 0.81 \\
$\mathrm{RE}^{7}$ & $75.6 \pm 23.0$ & $81.8 \pm 20.1$ & 0.28 \\
$\mathrm{MH}^{8}$ & $68.9 \pm 31.3$ & $79.2 \pm 20.0$ & 0.28 \\
$\mathrm{PCS}^{9}$ & $69.4 \pm 14.4$ & $74.2 \pm 16.1$ & 0.09 \\
$\mathrm{MCS}^{10}$ & $45.9 \pm 7.3$ & $52.1 \pm 8.3$ & 0.27 \\
\hline
\end{tabular}

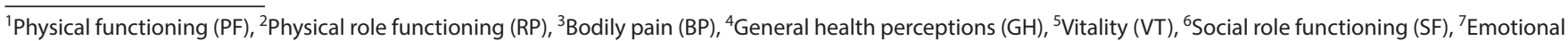
role functioning (RE), ${ }^{8}$ Mental health (MH), ${ }^{9}$ Physical component score (PCS), ${ }^{10}$ Mental component score (MCS) 
in patients who were admitted with tropical illness and sepsis compared to other causes. Severe acute pancreatitis patients had comparably higher mortality. As survivors of pancreatitis were on follow up in the gastro-surgery department of our Institute, patients with this diagnosis are over represented in our follow up study. Survivors of tropical illness are fewer in number as these patients had an acute illness from which they had recovered completely and hence, did not need long term follow up.

We used data for the general population of Australia for comparison of quality of life as comparable data for India was not available ${ }^{14,15}$. The data from our study shows comparable results from ICU survivors compared to the general population. The values were slightly less in terms of physical functioning and general health perceptions which contrast with data from developed nations where the emotional component is more affected. Possibly, since our patients are younger, they are more interested in their physical functioning as their income is dependent on it.

Kaarlola et $\mathrm{al}^{16}$ in a group of critically ill patients from Finland found much slower improvement in emotional parameters following ICU discharge. Flaatten et $\mathrm{al}^{17}$ found similar quality of life 2 years after ICU discharge compared to general population. Winters et $\mathrm{al}^{18}$ in a systematic review of all the quality of life related outcomes from septic ICU patients concluded that there is a need to look beyond 28 days mortality and into long term quality of life related outcomes. Pettilä et al $^{19}$ showed lower improvements in vitality and emotional parameters 1 year post ICU discharge.

We dichotomised our patients based on age, duration of mechanical ventilation and duration of stay in the ICU. We compared the quality of life parameters measured using the SF-36 form between the groups based on the above classification. Patients who were older than 50 years had a worse physical role function compared to younger patients. This could probably be because of weaker muscles and higher incidence of neurological problems in older age group. The patients who had more than 7 days stay on the ventilator had worse vitality, probably because these patients had weaker respiratory and cardiovascular function compared to those who could be weaned earlier. The patients who had more than 28 days' stay in ICU had more pain which was presumably due to residual neuromuscular weakness, need for invasive tubes and nutritional deficiencies.

The QALY was calculated from the SF-6D scorings ${ }^{20}$. The effective way of estimating the cost effectiveness of any therapy is by measuring the cost per QALY gained. In the setting of developed nations, US\$ 50,000 per QALY is a generally accepted upper limit. This cannot be a bench mark for a resource limited country like India. We estimate per capital GDP to be a bench mark for estimating this upper limit. This is roughly US\$50,000 for United States of America while for India it is US\$ 1800 as per 2016 International Monetary Fund calculations. The cost per QALY gained in our study was US\$ 1396. If we consider US\$1800 as an upper limit to cost effective therapy in India then the ICU care provided in our ICU may be considered cost effective.

The other concern is effect of age on post ICU outcomes and its cost effectiveness. Limitation of ICU beds and the cost associated sometimes makes the decision difficult when triaging of old patients is done. We divided our patient into two groups; more than 50 years or less than or equal to 50 years for the age related cost analysis. The cost per QALY was similar between the two groups: US\$ 1391 for younger patients and US\$1413 for older patients. This value was not statistically significant, but since the numbers in our study are small, we may get different results in larger studies. The life years gained was based on survival data from WHO for Indian population. The cost per life year gained was significantly more in older population. Inspite of this, the therapy was cost effective in older patients too.

\section{Limitations}

Our study has various limitations, the most important being the large number of survivors whom we could not contact. This is likely to introduce a bias, as those with whom we could establish contact could be different from the rest of the survivors. It is possible that the survivors whom we could contact were more concerned about their health. This factor may impact the quality of life. The age related data is from a very small population. Cost calculations only include the cost of ICU care and not the entire hospital stay. We believe that the results from our study may only be an indicator. These results need to be confirmed from larger and preferably, multicentric studies.

\section{Conclusion}

The quality of life after survival from ICU is as good as in the general population. The intensive care provided in our ICU is cost effective.

\section{References}

1. Bickenbach J, Fries M, Rex S, Stitz C, Heussen N, Rossaint R et al. Outcome and mortality risk factors in long-term treated ICU patients: a retrospective analysis. Minerva anestesiologica 2011;77:427-38.

2. Oeyen SG, Vandijck DM, Benoit DD, Annemans L, Decruyenaere JM. Quality of life after intensive care: a systematic review of the literature. Critical care medicine 2010;38:2386-400.

3. Herridge $M$, Cox $C$. Linking ICU practice to long-term outcome: fostering a longitudinal vision for ICU-acquired morbidity. American journal of respiratory and critical care medicine 2012;186:299-300.

4. Laupland KB, Kirkpatrick AW, Kortbeek JB, Zuege DJ. Long-term mortality outcome associated with prolonged admission to the ICU. Chest 2006;129:954-9.

5. Garcia Lizana F, Peres Bota D, De Cubber M, Vincent JL. Long-term outcome in ICU patients: what about quality of life? Intensive care medicine 2003;29:1286-93.

6. Carden GP, Graham JW, McLennan S, Celi LA. Long-Term Outcome of Long Stay ICU and HDU Patients in a New Zealand Hospital. Critical care and shock 2008;11:26-34.

7. Garratt AM, Ruta DA, Abdalla MI, Buckingham JK, Russell IT. The SF36 health survey questionnaire: an outcome measure suitable for routine use within the NHS? Bmj 1993;306:1440-4.

8. Jenkinson C, Coulter A, Wright L. Short form 36 (SF36) health survey questionnaire: normative data for adults of working age. Bmj 1993;306:1437-40.

9. Lau RS, Johnson S, Kamalanabhan TJ. Healthy life expectancy in the context of population health and ageing in India. Asia-Pacific journal of public health 2012;24:195-207.

10. Chattopadhyay A, Sinha KC. Spatial and gender scenario of literate life expectancy at birth in India. Asia-Pacific journal of public health 2010;22:477-91.

11. Sassi F. Calculating QALYs, comparing QALY and DALY calculations. Health policy and planning 2006;21:402-8.

12. Graf J, Wagner J, Graf C, Koch KC, Janssens U. Five-year survival, quality of life, and individual costs of 303 consecutive medical intensive care patients--a cost-utility analysis. Critical care medicine 2005;33:547-55.

13. Jegers $M$, Edbrooke DL, Hibbert CL, Chalfin DB, Burchardi $\mathrm{H}$. Definitions and methods of cost assessment: an intensivist's guide. ESICM section on health research and outcome working group on cost effectiveness. Intensive care medicine 2002;28:680-5.

14. Lin M, Ward JE. Reliability of the MOS SF36 health status measure in Australian general practice. Australian family physician 1998;27 Suppl 2:S94-8. 
15. Malamardi SN, Kamath R, Tiwari R, Nair BV, Chandrasekaran V, Phadnis S. Occupational stress and health-related quality of life among public sector bank employees: A cross-sectional study in Mysore, Karnataka, India. Indian journal of occupational and environmental medicine 2015;19:134-7.

16. Kaarlola A, Pettila V, Kekki P. Quality of life six years after intensive care. Intensive care medicine 2003;29:1294-9.

17. Flaatten $H$, Kvale R. Survival and quality of life 12 years after ICU. A comparison with the general Norwegian population. Intensive care medicine 2001;27:1005-11.
18. Winters BD, Eberlein M, Leung J, Needham DM, Pronovost PJ, Sevransky JE. Long-term mortality and quality of life in sepsis: a systematic review. Critical care medicine 2010;38:1276-83.

19. Pettila $V$, Kaarlola A, Makelainen A. Health-related quality of life of multiple organ dysfunction patients one year after intensive care. Intensive care medicine 2000;26:1473-9.

20. Mazari FA, Shahin Y,Khan JA, Samuel N, Carradice D, Mccollum PT, Chetter IC et al. Comparison of Use of Short Form-36 Domain Scores and Patient Responses for Derivation of Preference-Based SF6D Index to Calculate Quality-Adjusted Life Years in Patients with Intermittent Claudication. Annals of vascular surgery 2016;34:164-70. 